\title{
Metodologia e métodos de análise em clínica da atividade
}

\author{
Jean-Luc Roger ${ }^{1}$ \\ Conservatoire National des Arts et Métiers (Paris, França)
}

\begin{abstract}
Este artigo trata da metodologia na clínica da atividade. Principia com a definição da noção de atividade, distinguindo-a da atividade realizada e do real da atividade. Estruturado pelos conflitos entre três polos, o próprio sujeito, os outros e seu objeto, esse real da atividade não é passível de ser conhecido ou transformado de modo direto, nem pelo sujeito nem por qualquer outro. Acessar a atividade implica, então, proceder de maneira indireta. $\mathrm{O}$ artigo mostra por que e como, para atingir esse fim, se deve "provocar" o desenvolvimento. Essa metodologia usa métodos - autoconfrontação e instruções ao sósia - que permitem a instalação de uma atividade nova, retomando e fazendo reviver os conflitos do real da atividade e as soluções que lhes são dadas. Por fim, um estudo de caso permite ilustrar os efeitos dessa metodologia desenvolvimental em suas duas vertentes: a do aumento do poder de agir e da ampliação do manejo de seu ofício pelos sujeitos em questão e a dos conhecimentos científicos dos processos em jogo.
\end{abstract}

Palavras-chave: Atividade, Real da atividade, Desenvolvimento, Autoconfrontação, Instruções ao sósia.

\section{Methodology and analysis methods in clinic of activity}

This article focuses on the methodology of the clinic of activity. It begins by defining the notion of activity distinguishing the activity performed and the reality of activity. Structured by conflicts within and between three poles, self, others and its object, the reality of activity is not directly knowable or convertible, neither by the subject nor by any other. The assessment of the activity implies in doing so indirectly. The article shows why and how it is necessary, to reach its end, to "cause" the development. This methodology implements methods, "the selfconfrontation", "instruction to the double", that allow the establishment of a new activity and by resuming the replay of conflicts of reality of activity and the solutions that are achieved. Finally a case study illustrates the effects of this developmental methodology in its two sides: that of increasing the power to act and broadening the ownership of their work by the subjects concerned, that of scientific knowledge of the processes involved.

Keywords: Activity, Real of activity, Development, Crossed self-confrontation, Instruction to the double.

\section{A noção de atividade}

$\mathrm{P}$ ara abordar a questão da metodologia e dos métodos em Clínica da Atividade, é preciso, de início, definir a noção de atividade tal qual ela é aí empregada, pelo menos naqueles aspectos que serão úteis para nossa reflexão. O que implica tratá-la sob dois ângulos, inseparáveis, mas distintos: 1) o ângulo da atividade realizada. Nós a designaremos como uma ação constituída de gestos (uso de instrumentos, posturas, atitudes etc.) e de atos linguageiros (intervenções orais, trocas dialógicas etc.); 2) o ângulo do conjunto do que se produz no desenvolvimento da atividade, muito mais amplo, englobando dimensões subjetivas. É um real da atividade não aparente por natureza (Clot, 2002).

É esse real da atividade que anima o profissional quando este age, quase sempre, a despeito dele mesmo. $\mathrm{O}$ real da atividade é um espaço de conflitos entre (e no interior de) diversos polos aos quais aquele que age dirige sua atividade. $O$ primeiro desses polos é o objeto de trabalho.

Definiremos o trabalho do professor, que irá nutrir nossas ideias durante toda essa exposição, como pluridimensional, constituído ao mesmo tempo por conhecimentos e saberes, 
por formas de organização e por práticas a serem apropriadas pelos alunos, por modalidades de relações consigo mesmo, com os outros e com o mundo que essas práticas supõem, as quais o professor deve levar os alunos a adotar (Roger, Ruelland \& Yvon, 2001).

Um segundo polo é a atividade dos outros dirigida para o mesmo objeto, outros imediatamente presentes - os alunos -, mas também outros cuja atividade intervém constantemente sob uma forma ou outra: criadores de programas e de manuais, aqueles que fazem as prescrições em nível administrativo ou social, colegas, hierarquia pedagógica, pais de alunos etc. Mas o real da atividade implica também um terceiro polo, que é o próprio sujeito. Dirigida ao objeto e aos outros, sua atividade se dirige também a ele mesmo.

Agir é, portanto, a cada momento, se encontrar em meio a conflitos técnicos, sociais ou pessoais do real da atividade, em que a relação consigo mesmo, nas suas contradições, é confrontada em permanência com o objeto da atividade e com a atividade dos outros sobre o mesmo objeto em sua diversidade e em suas próprias contradições. Agir é, então, se engajar necessariamente, mas de forma geralmente naturalizada pela experiência, na solução desses conflitos: essa será uma ação efetiva, atividade realizada que emerge do real da atividade. No entanto, o gesto, o ato linguageiro, no qual aquele que age finalmente se engajou, é apenas uma opção que surgiu dentre outras possíveis, mas, por diversas razões, não se pôde realizar naquele momento (Vygotsky, 2003). Resta, portanto, na atividade, toda sorte de resíduos, os possíveis não realizados que vão habitar, nutrir, às vezes parasitar, a atividade futura ou então lhe abrir novas possibilidades. O que não foi feito, porque pode ser realizado mas ainda não foi feito, ou porque é não realizável, tudo o que deve ser refeito etc., tudo isso é muito real e pesa muito no psiquismo de cada um e nas suas condutas futuras. Portanto, se queremos alcançar o que existe de essencial na atividade, só podemos compreendê-la como ultrapassando amplamente o que foi realizado e que é observável, concebendo-o ao mesmo tempo como parte dessa atividade.

O instante da atividade se inscreve numa história. Esse instante, segundo Vygotsky, não concerne apenas ao passado. A história é, de forma bem precisa, a transformação do passado em futuro ou o fracasso dessa transformação. Estamos sempre simultaneamente em dois planos: aquele que é e o que já foi. A forma fossilizada é a extremidade do fio que liga o presente ao passado. Assim, o presente é um momento para o qual converge de modo singular um conjunto de antecedentes que poderiam ter sido outros e um futuro de saídas possíveis (Vygotsky, 1978).

Essa análise se aplica perfeitamente à atividade, que a cada momento retoma e transforma toda a história pessoal dos conflitos passados de atividade. Esse é, então, um processo histórico-desenvolvimental, no qual se "vincula ou desvincula o individual e o social, o sujeito e a organização do trabalho, os sujeitos entre si e os sujeitos com os objetos que os mobilizam" (Clot, 2008, p. 10). Nesse processo, se recicla tudo o que a atividade passada deixou como resíduo de possíveis não realizados. Recicla-se também todo o histórico de soluções que permitiram, pessoal e coletivamente, libertar desses conflitos o estoque de modos de fazer técnicos e simbólicos acumulados, fossilizados na história de uma profissão. Esse histórico de soluções configura o "gênero profissional", patrimônio coletivo incorporado individualmente como recurso dialógico da atividade pessoal, que permite àquele que age responder ao ofício. A atividade inscrita nessa história pessoal e coletiva vai - ou não - permitir ao sujeito lidar com o contexto no qual vive para recriá-lo e, assim, fazer que o trabalho continue defensável, a fim de que aqueles que o realizam possam manter a distância o desgaste, o sofrimento e a angústia. A questão é, então, o desenvolvimento possível ou impossível. 


\section{Metodologia indireta e métodos de análise}

No plano da metodologia, a concepção de atividade como um momento de um processo histórico-evolutivo conduz a se diferenciar de análises que privilegiam um ou outro componente da atividade.

A Clínica da Atividade não é uma prática de observação ou de análise do vivenciado como tal, seja quando se apresenta sob o ângulo do subjetivo ou da ação efetuada (Clot, 2008, pp. 179-230). É uma clínica em que a atividade na sua totalidade, o real da atividade e a atividade realizada, é compreendida como aquilo que guarda ou não - ou guarda insuficientemente - essa experiência viva. Ela então vai poder se fixar como seu objeto, compreender sob quais condições essa experiência vai poder se fazer, segundo quais processos do desenvolvimento da atividade.

Mas o real da atividade não é passível de ser conhecido diretamente, nem pelo sujeito nem por um interlocutor. Ele também não é acessível pelos métodos de observação. Ele somente se manifesta pela atividade realizada, a ação efetiva, que o exterioriza sem traduzi-lo exatamente - nem inteiramente - e sem permitir que ele seja alcançado.

Alcançar o real da atividade implica, então, proceder de maneira indireta. É preciso "provocar" o desenvolvimento para poder estudá-lo e compreender seus movimentos. Será necessário organizar "repetições sem repetição". Essa metodologia cria processos que permitem, dentro de um contexto regulado, fazer emergir uma nova atividade que, de uma maneira ou de outra, retomará e fará surgirem os conflitos técnicos, sociais ou pessoais do real da atividade e as soluções que são apresentadas. Ela visa a organizar, no quadro de uma intervenção com profissionais voluntários, uma segunda atividade sobre uma primeira atividade de trabalho.

Esse retorno sobre a ação efetiva diz respeito, em primeiro lugar, aos sujeitos envolvidos. Trata-se, para eles, da ocasião de refazer um histórico das atividades "paralisadas", "desmontando o molde" ao qual estavam presas e refazendo o jogo do real da atividade e suas contradições, seus "resíduos", de conscientizar e de compreender para poder fazer desses resíduos um recurso ou qualquer outra coisa. É somente quando a experiência serve para fazer outras experiências que mantemos as rédeas da história, não tentando negá-la mas intermediando o seu desenvolvimento.

Mas a intervenção é também indispensável para o conhecimento que aí se encontra sua "matéria-prima" para uma análise dos processos do desenvolvimento da atividade. Porque é transformando as ações efetivas em recursos para outras ações que o real da atividade se manifesta nos seus desenvolvimentos.

Estamos, então, diante de uma dupla dinâmica de intervenção em Clínica da Atividade: a do desenvolvimento do poder de agir dos sujeitos implicados; a da elaboração de conhecimentos sobre os processos de desenvolvimento. Nessa dinâmica dupla, indivisível, nenhum desses elementos pode existir sem o outro. De um lado, ambos encontram sua origem no mesmo processo de desenvolvimento da experiência, necessária a ambos. De outro, o conhecimento científico não pode ser afastado do desenvolvimento da ação em que se encontra sua matéria-prima; o desenvolvimento da ação em Clínica de Atividade se efetua em um cenário elaborado sobre a base teórica da necessidade de desenvolver para compreender.

Diversos métodos podem ser usados, segundo diferentes modalidades, para permitir uma observação e uma interpretação da atividade realizada, mais exatamente fazendo-a repetirse em outro contexto. Para que esse retorno sobre a ação efetiva dê resultados, ele não pode se reduzir a um face a face do indivíduo consigo mesmo. A consciência, diz Vygotsky, é "um contato social consigo mesmo", e o estabelecimento de dispositivos permitindo ver sua atividade pelos olhos das atividades dos outros é um elemento decisivo (Vygotsky, 2003, p. 91, apud Clot, 2008). Esses métodos permitem, igualmente, em um coletivo transformado em um 
novo protagonista, confrontar-se com outras experiências, aquelas vivenciadas por pares, membros do mesmo ofício, o que pode ser fator de controvérsias. Visa-se assim o aprofundamento da investigação. Os métodos exigem, então, que se constituam grupos de trabalho com profissionais que estejam em busca de aumentar seu poder de agir e ampliar seu domínio sobre seu ofício.

A instrução ao sósia é um "meio desviado", um "contato social" artificial consigo mesmo. Pede-se ao indivíduo, na presença dos outros membros do grupo de trabalho, que dê a um interlocutor - o clínico é quem faz o sósia - as instruções mais precisas para que este possa substituí-lo no trabalho, sem que essa substituição seja perceptível aos outros. As solicitações de precisão do sósia visam conduzir o indivíduo a se explicar com mais clareza e explicitar os detalhes de suas ações. $O$ trabalho prossegue com uma transcrição do diálogo pelo próprio indivíduo, acompanhada de seus comentários antes de ser restituída ao grupo de trabalho.

Esse procedimento visa a provocar uma "reentrada" na ação e, por seu intermédio, a entrada em cena dos componentes e contradições do real da atividade. Pode resultar daí uma repetição sem repetição, ao se trabalhar a ação em uma outra atividade, com o sósia, em que a ação anterior serve agora de recurso. A consciência é esse desdobramento do vivido, revivido para viver outra coisa. "A representação de um sósia é a representação da consciência mais próxima da realidade”, observava Vygostky (2003, p. 91, apud Clot, 2008).

Já o método da autoconfrontação se baseia na organização de uma atividade dialógica plena de dissonâncias: atividade que vai se dar em um diálogo interior do sujeito consigo mesmo, e com seus interlocutores, que são os membros do grupo de trabalho ao qual ele pertence. A oportunidade para esse diálogo interior se dá quando o sujeito é confrontado ao vídeo de sua atividade realizada. Em um primeiro momento o sujeito assiste a essa gravação na companhia do clínico da atividade. As surpresas, por vezes muito significativas diante do que ele faz efetivamente com relação ao que acreditava ter feito, os inesperados pontilhando a sua ação, que ele descobre no vídeo, o incitam a reflexão. As demandas de precisões e de explicitações, feitas pelo clínico, contribuem para seu aprofundamento. A essa autoconfrontação simples se sucede uma autoconfrontação cruzada, com um colega, na presença do clínico. Cada qual assiste, e comenta, à atividade realizada pelo outro, e cada um vê o que fez com os olhos da atividade do outro. O jogo de discordâncias entre os contextos propostos, o da atividade realizada e o da atividade segunda sobre essa atividade realizada, permite, muitas vezes, relançar a repetição de um funcionamento além de sua repetição, a fim de que a atividade de cada um e do coletivo retome seu curso. $O$ desenvolvimento pode se efetuar então por rearranjos dos conflitos do real da atividade, mas também pelo desenvolvimento de uma ação mais eficaz, graças ao acesso a maneiras de fazer, técnicas e simbólicas, dos outros, por meio do exame e da transformação dos seus próprios modos de fazer. As atividades de trabalho a serem analisadas não estão "todas prontas" à espera de uma explicitação, e a atividade do clínico não consiste em reencontrá-las como processos suscetíveis de serem validados por meio da análise. Nós sabemos que essa análise deixa tais atividades intocadas e que ela as desenvolve, no sentido forte do termo. Transformando-se em linguagem, as atividades se reorganizam e se modificam. A linguagem graças à qual o sujeito se dirige a seu interlocutor, na troca que constitui o comentário sobre sua atividade,_retorna para o objeto analisado. As atividades, então, não se expressam só nas palavras, que lhe serviriam apenas de veículos amorfos para falar a seu respeito. Graças à linguagem dirigida ao outro, o sujeito realiza, no sentido forte do termo, suas atividades. Portanto, sua "realização" é determinada pelo contexto em que suas atividades são mobilizadas. Tantos contextos, tantas "realizações" possíveis, fontes potenciais de novos desenvolvimentos ou de impedimentos imprevistos.

No retorno sobre o vivido a fim de viver outros vividos, que é a Clínica da Atividade, a instrução ao sósia e a autoconfrontação são técnicas comprovadas. Mas elas por si só não são suficientes. Elas só atingem validade total na medida em que se inscrevem em um processo de desenvolvimento que as abrange e as ultrapassa.

\section{4}


Esse processo começa já na fase preparatória da intervenção, na constituição dos grupos de trabalho e nas reuniões em que cada grupo debate sobre quais são as situações problemáticas, os dilemas de trabalho encontrados no exercício do ofício, visando a determinar os momentos ou os eventos mais pertinentes para a análise. Para além da simples narrativa do vivido ou das análises generalizantes que podem ser feitas, o que está em jogo aqui é incitar os participantes a começarem a centrar seu olhar e reflexão sobre as atividades que lhes são próprias. Isto é, de alguma forma envolvê-los em um processo de auto-observação (Roger, 2007).

A implementação de técnicas de instrução ao sósia e de autoconfrontação se prolonga em algumas sessões dos grupos de trabalho e sessões de restituição ao meio profissional e ao contratante da intervenção. Mas o processo pode se prolongar de outra maneira. Em uma intervenção de longa duração, efetuada com os profissionais da educação secundária, os grupos de trabalho se reúnem aproximadamente duas vezes por trimestre durante vários anos, para discutir a partir dos traços acumulados: montagens de vídeo das atividades ou das autoconfrontações, vídeos de instruções ao sósia, transcrições de passagens de instruções ao sósia.

Para alguns - professores de diversas disciplinas - a abordagem foi muito além. $\mathrm{Na}$ conclusão das fases anteriores, eles se colocaram a questão da utilização (de início, com seus colegas, mas também com sua hierarquia e com a instituição) daquilo que tinham adquirido como modo de apreender os problemas do ofício. A partir de suas necessidades e de forma experimental, organizaram uma intervenção em que, mesmo exercendo suas atividades docentes, eles mesmos se colocavam como consultores junto com seus colegas, na função anteriormente exercida pelo consultor externo, membro da equipe de Clínica de Atividade. Tornando-se profissionais consultores, supervisionados por pesquisadores-consultores, esses professores encontraram aí a ocasião de se apropriar das técnicas e das noções essenciais da Clínica de Atividade. Mas eles também mobilizaram o conhecimento que tinham de seus ofícios e o modo de desenvolvê-lo adquirido anteriormente, para nutrir ao mesmo tempo o processo de desenvolvimento dos membros do grupo de trabalho no qual estavam intervindo e prosseguir com seu próprio desenvolvimento. A experiência ainda está em curso, mas já se pode dizer que a combinação de responsável pela continuidade do quadro clínico e de conhecedor do ofício, pelo fato de exercer esse ofício, é uma possibilidade real e em geral frutífera. Se essa constatação se confirmar, algumas perspectivas podem se abrir para um autoenquadramento, sob certas condições, de um meio profissional, no que concerne ao desenvolvimento do poder de agir e da retomada do controle sobre seu ofício.

O que na verdade unifica as diversas maneiras de engajar os indivíduos em uma abordagem desenvolvimental é realmente a eficácia, é a natureza do que é produzido. Trata-se essencialmente de uma nova maneira de enfrentar as realidades da atividade profissional, a partir do realizado e da recolocação em cena do real da atividade. A confrontação ao que se faz, sua explicação para si e para os outros, as controvérsias profissionais que surgem a respeito das maneiras simbólicas e técnicas de fazer, a exploração de novas pistas de reflexão e de ação, tudo isso incita à superação do modo de fazer e dizer habituais. Uma linguagem "verdadeira" se apresenta e se liga, muitas vezes a partir de detalhes, ao real das situações e às suas questões, linguagem cuja tonalidade se percebe quando ela se manifesta no curso das trocas dialógicas. No diálogo interno, a dobra acontece quando se faz referência ao que aconteceu no trabalho coletivo e isso contribui para ultrapassar o que já foi pensado, o já dito, o que já foi feito.

Uma verdadeira aprendizagem se efetua, assim, com o desatamento dos nós do para a criação de novos caminhos. 


\section{Análise, desenvolvimento e conhecimento: um caso}

Um estudo de caso vai nos permitir ilustrar os efeitos da metodologia da Clínica de Atividade nas suas duas vertentes: aquela do desenvolvimento do poder de agir e da apropriação do ofício pelos sujeitos implicados; e aquela do conhecimento científico dos processos em questão. Nesta apresentação, não iremos separar os dois aspectos, tentando ligar, em cada ponto abordado, o acompanhamento e os avatares do desenvolvimento e as noções ou conceitos que permitam analisar os processos em ação.

Apresentarei o caso de F. Trata-se de uma jovem professora de história e geografia que, há dez anos, ensina em uma escola "numa zona sensível" do subúrbio parisiense. Ela foi filmada em uma classe de segunda série onde ela propõe a seus alunos o estudo de documentos sobre o período do Terror à época da Revolução Francesa de 1789 (anexo 1). F. seguiu, em Clínica da Atividade, todas as trajetórias descritas acima. Ela é hoje uma profissional - participante ativa do processo de intervenção. Por outro lado, ela também efetuou um trabalho de levantamento e análise de sua própria evolução no quadro da Clínica da Atividade. A primeira etapa consiste em uma série de anotações rápidas (anexo 2) produzidas por ela após o encontro face a face com o pesquisador-clínico, ocasião em que sentiu um mal-estar persistente ao rever as imagens dos vídeos de sua atividade, as quais se tornaram o objeto de uma nova discussão. Este episódio foi a origem de todo um processo reflexivo, marcado por um número notável de escritos e de intervenções de $\mathrm{F}$. em diversos contextos. As análises apresentadas abaixo se inspiram fortemente nesse material. De certa forma, o que falamos aqui nos é dado por essa professora.

O primeiro comentário será sobre a mediação da atividade. Aqui, a atividade, como podemos constatar, está fortemente determinada pelos instrumentos técnicos e psicológicos que estão em jogo: os documentos e seus comentários orientam a atividade que é firmemente enquadrada por uma rede de concepções e representações relativas ao aprendizado do aluno $(\mathrm{A} 1,21){ }^{2}$ Daí resulta um bloco de ações em que se repete o fazer estabelecido, em que os resíduos das atividades anteriores são reinvestidos sempre da mesma maneira, conduzindo a um sentimento de fracasso repetido, várias vezes reafirmado (AI, 15-16). No entanto, ao mesmo tempo, esses instrumentos são também a origem de conflito na atividade, em que se opõem, de um lado, a instituição como destinatário, instituição cujas ordens e instruções lhe parecem ser a origem dessa forma do fazer e de representar o que temos que fazer (AI, 21); e, por outro lado, o que essa atividade devolve para a própria F.: a questão, quase impronunciável, do conteúdo em termos de conhecimentos (A1, 19-25). O sentido da ação se perde, na medida em que os objetivos estabelecidos para a ação não correspondem, nem mesmo parcialmente, aos motivos daquela que a realiza.

Para F., a percepção desses conflitos não é espontânea nem evidente. É somente o retorno às imagens de sua ação realizada que lhe permite identificar e tentar especificar um vago mal-estar que ela sente durante sua aula. É um detalhe - uma breve parada da aula acompanhada de uma mudança de atitude (AI, 5-10) -, que passa despercebido aos olhos de outros, que lhe permite identificar a situação que lhe é problemática sem que, em um primeiro momento, possa ir mais longe na análise. Mas é a segunda atividade sobre a primeira que dá a F. a oportunidade de desnaturalizar sua ação e reavivar questões sentidas por ela de maneira recorrente. Resulta daí uma forte emoção que se manifesta de várias maneiras ao longo das autoconfrontações simples e cruzadas que se seguem. São alguns risos, silêncios, usos frequentes do já pensado e do já dito quanto às questões do ofício, racionalizações explicativas (AI, 26-29) etc. No entanto, todos esses momentos de hesitação não são apenas mecanismos de defesa, ou a simples manifestação da dificuldade de apropriar-se das questões. Eles remetem, ao mesmo tempo, a um processo necessário à Clínica de Atividade: o poder de ser afetado, condição

2 Os códigos a seguir referem-se à numeração adotada no anexo I, referente à transcrição da aula ministrada pela professora em questão. 
incontornável de um possível desenvolvimento. Fortemente presente aqui, esse poder de ser afetado não é sempre encontrado em todos os participantes, ou ocorre com uma intensidade variável. São muitas vezes mecanismos de defesa que estão em jogo, bloqueando as possibilidades de engajamento no processo proposto. No entanto, acontece também que desbloqueios se produzam no decorrer das diversas fases, desde que o consultor cuide delicadamente da preservação do enquadre clínico.

Um segundo ponto diz respeito ao diálogo. Ele se desenvolve a partir do acontecimento registrado por $\mathrm{F}$. O já pensado e o já dito, o discurso conveniente ao meio, sobre o que convém fazer, nutre amplamente as primeiras análises de F. (AI, 21; 26-29), as quais, no entanto, não são suficientes, perante as questões do clínico, para explicar o acontecimento por ela vivenciado. A contradição sentida entre o que é testado com os alunos - aquisição de métodos e a atividade - e a questão do conteúdo continua opaca. A análise se resume a uma falta de equilíbrio entre esses dois aspectos na condução da aula. Entretanto, os "eu não sei" se sucedem, mostrando certa desconstrução do discurso estabelecido (AI, 25). E a autoconfrontação cruzada mostra uma reconstrução sistemática (AI, 26-29) que esbarra na reação da colega cuja expertise é totalmente contrária à lógica, artificial aos seus olhos, posta em prática por $\mathrm{F}$. (AI, 30, 32).

O acontecimento que é aqui objeto de atenção constitui uma espécie de "embate dialógico" que salta de uma situação a outra, de um interlocutor a outro, provocando uma luta dialógica entre três protagonistas: a própria F., seus interlocutores - o clínico, sua parceira da autoconfrontação e seus outros colegas -, mas também o ofício, ao qual uns e outros se dirigem como sobredestinatários de suas trocas diretas. Essa luta dialógica se dá sobre o significado da situação, por meio de certas palavras como conteúdo, conhecimentos que irão fazer de forma prolongada o objeto de interpretações e debates (A2, 13-17).

No entanto, no caso aqui apresentado, a forte presença de sentimentos vai se constituir em um problema e limitar, durante um tempo, a eficácia dessa luta dialógica. F. não vai estar em condições de se livrar realmente do seu bloqueio emocional sentido no momento de sua autoconfrontação simples e que fala sobre a contradição entre as modalidades de aprendizagem de métodos pelos alunos e o conteúdo. Esse bloqueio perdura no período das reuniões de grupo de trabalho que acompanham as autoconfrontações e durante as quais se retorna, em várias ocasiões, aos vídeos, às vezes transcritos, de seu curso ou das autoconfrontações. Para ela, será uma fase difícil cuja lembrança ainda está viva.

No entanto, sua participação no trabalho de análise proposto vai, para ela, manter seu sentido. Sua participação lhe permite de fato satisfazer uma antiga motivação: a de romper com o isolamento, que é uma das características fortes da atividade de ensino no secundário francês $(\mathrm{A} 2,3)$. O coletivo vai rapidamente se tornar, para ela, por um longo tempo, um instrumento psicológico essencial, na medida em que ele sempre põe em questão aquilo que ela sente (A2, 13). A partir desse momento ela poderá ter uma evolução que, de alguma maneira, se justapõe ao bloqueio emocional vivido anteriormente. Essa evolução se dá na esfera afetiva, pois F. tem a impressão de ser responsável - culpada - pelas dificuldades encontradas no seu trabalho de ensinar (A2, 4). Essa não é uma questão anódina, já que, no contexto atual, a instituição tende a colocar sobre os professores a responsabilidade essencial pelos problemas do sistema educativo. No nível individual, F., como muitos dos seus colegas, sofre essa pressão, que contribui, ao tentar escapar dela, para aprisioná-la nas maneiras institucionais do fazer e do pensar, que ela repete e da qual não pode escapar.

Mas sua participação no grupo de trabalho de Clínica de Atividade revelou a ela que seus colegas sofrem as mesmas dificuldades. O diálogo com o clínico, com sua parceira de autoconfrontação, a fez questionar se ela não poderia ir mais longe no momento. Em seguida na medida em que as dificuldades não parecem ser unicamente dela -, F. vai progressivamente alterar a função dos endereçamentos de sua atividade. Até então voltado para o "outro" que 
representa a instituição, tal endereçamento consistia em responder ao que $\mathrm{F}$. preconizava quanto à construção de técnica e à concepção simbólica das tarefas $(\mathrm{A} 1,21)$. O fato de as dificuldades serem partilhadas com seus colegas a leva a questionar essa adesão às orientações institucionais, cuja pertinência torna-se problemática a seus olhos. F. também vai modificar a sua relação com os colegas, que se tornam parceiros e cujas maneiras de fazer e de pensar a interpelam $(A 2,9)$. Ela também vai modificar o modo como sua atividade retorna para si mesma e se autorizar, doravante, uma margem maior de autonomia, experimentando modestamente outras formas do fazer $(\mathrm{A} 2,9-10)$. Observamos a migração progressiva da função de diferentes endereçamentos da atividade. É isso, sem dúvida, que provoca uma desresponsabilização, F. não carrega mais sozinha o peso das dificuldades encontradas no seu ensino, porque outros também as enfrentam, outros as encaram cada um a seu modo, e,inspirando-se neles, ela mesma pode também fazê-lo. De certa maneira, essa transformação dos sentimentos quanto à questão da responsabilidade vai lhe abrir a possibilidade de retomar com mais serenidade a contradição surgida no momento da autoconfrontação simples entre métodos e conteúdo.

É na ampliação do perímetro da atividade dialógica que F. encontrará recursos para uma nova extensão do seu poder de agir. Depois de algumas sessões de seu grupo de trabalho, um encontro será organizado com outro grupo, de história e geografia, que vivenciou paralelamente a mesma experiência. Esse encontro vai enriquecer notavelmente o diálogo, na medida em que a confrontação de experiências mais diversificadas permite colocar em jogo novas formas de fazer e representar o ofício. Nesse caso, essa expansão tornou-se decisiva, levando-se em conta que o grupo ao qual $\mathrm{F}$. pertencia não tinha professores com suficiente reflexão epistemológica, quanto às disciplinas ensinadas, para alimentar as trocas dialógicas. Esse era, no entanto, o caso do outro grupo de trabalho. Uma distinção necessária é feita entre conhecimento factual e processo histórico, o que vai interpelar F. Ela encontra aí a ocasião de colocar em curso uma nova migração funcional. Essa migração provém de uma transformação do objeto da atividade em termos cognitivos. Até esse momento tratava-se essencialmente de familiarizar seus alunos a métodos que daí em diante se tornam meio de alimentar a reflexão em torno de conceitos da disciplina ensinada (A2, 16-17). Essa transformação de objeto conduz a um desenvolvimento do poder de agir pela mutação das maneiras de fazer - novas maneiras mais eficientes de fazer os alunos trabalharem -, evolução que acompanha o desenvolvimento cognitivo quanto à natureza da disciplina ensinada. No fim das contas, ela faz migrar o antigo objetivo da ação para atingir um novo objetivo, conforme as aspirações que ela havia expressado no decorrer de sua autoconfrontação simples: fazer conhecimentos chegarem aos seus alunos, mas conhecimentos entendidos doravante com um novo significado, não por si mesmos, mas como suporte a uma atividade conceitual. As coisas retomam seus lugares, e a ação tem um sentido.

\section{Conclusão}

Eis alguns elementos sobre os processos que se dão no desenvolvimento do poder de agir e na apropriação, de forma ampliada, do ofício, assim como das noções e conceitos que permitem acessar e analisar esses processos. Os limites dessa intervenção não nos permitem aprofundar mais esses dois aspectos.

No entanto, a título de conclusão, vamos sublinhar que o desenvolvimento só se efetua quando o engajamento afetivo dos participantes é real, e nada pode garantir que ele se produza para cada um, a cada vez. Não é um processo contínuo nem linear. Requer uma interdependência e uma circulação entre dimensões afetivas e cognitivas. É necessário que os componentes da atividade migrem de função. Suas manifestações combinam o aumento da 
eficiência na realização das tarefas e o engendramento de novos sentidos. Resultam daí uma maior eficácia da ação e o desenvolvimento do poder agir.

Como o caso exposto aqui nos mostra bem, tudo isso se produz com a mediação do coletivo em que, em diversas configurações técnicas, se expõem e se confrontam as formas do fazer e de pensar, em que se desenvolvem controvérsias entre pares, dirigidas também ao sobredestinatário, que é o ofício. O ponto de partida é um retorno documentado sobre o vivido, nos seus detalhes, e a análise para os interessados na atividade afetiva. $\mathrm{O}$ meio usado para essa análise é a atividade dialógica, quando ela se centra sobre o que é difícil compreender e dizer.

\section{Referências}

Clot, Y. (2002). La fonction psychologique du travail (3를 ed. revista e ampliada). Paris: PUF.

Clot, Y. (2008). Travail et pouvoir d'agir. Paris: PUF.

Roger J-L., Ruelland, D. \& Yvon F. (2001). Interrogations pour une analyse de l'activité enseignante. Éducation permanente, 146, 115-126.

Roger, J-L. (2007). Refaire son métier. Toulouse: Erés.

Vygotsky L. (1978). Mind in society: the development of higher psychological process. Cambridge: Harvard.

Vygotsky, L. (2003). Conscience, inconscient, émotions. Paris: la Dispute.

\section{Endereço para correspondência \\ jld1.roger@orange.fr}

Recebido em: 21/08/2012

Revisado em: 08/04/2013

Aprovado em: 18/04/2013

\section{Anexo 1: transcrição do curso}

1. F.: A professora que dá a aula (classe secundária, sobre a Revolução Francesa de 1789)

2. SC: Sua colega

3. E: Aluno

4. Ch.: O pesquisador

5. F.: É uma lei relativamente arbitrária. O que vai ser... Qual é a punição? Qual é a punição, qual a penalidade que vai pesar sobre essa gente? 6. E.: A morte...

7. F.: Eles podem de fato ser executados...

8. Então a lei dos suspeitos deve ser usada para lutar contra os inimigos, na realidade do regime. É uma lei totalmente arbitrária...

9. Para salvar a República, para lutar contra os inimigos do regime, e é uma lei arbitrária.............

10. Bem, seguindo... Quais são as outras áreas?

11. Ch.: Isto te causa um problema?

12. F.: Aí, sim.

13. Ch.: É verdade? E por quê?

14. F.: Eu estou tentando refletir, dizendo a mim mesma, que coisa, eu não lhes disse isso, eu passei, eu passei ao largo do Terror. Foi o que eu disse a mim mesma, é por isso que existe um momento de... É... Eu me faço todas essas questões, aí realmente, aí tem um momento de flutuação aí para mim. Eu disse a mim mesma: eu passei ao largo do Terror, totalmente, eu realmente tive a impressão de passar ao largo. Isso, tem níveis, enfim, graus de fracasso também, de... tem pequenas coisas, às vezes, que não me satisfazem, mas isso são pequenas coisas... então eu... Não é muito grave. Isso é mais, é mais algo que contraria, eu acho...

15. Ch.: Aí você tem um sentimento de fracasso?

16. F.: Sim, sim, sim, a respeito dessa aula aí, sim. Sobretudo que... aí eu estava sem fôlego, enfim era... eu passei ao largo de muitas coisas... Para o Diretório também, veremos após, eu não estava tranquila, eu não fiquei à vontade... Porque eu tenho a impressão de resumir tanto já no final, notadamente o Diretório e tudo, que finalmente não faz mais nenhum sentido...

17. F.: É engraçado, porque quando eu olho tudo isso, é a reflexão que eu estava me fazendo, quando eu vejo o trabalho de preparação que isso demanda, eu me digo, enfim... Nós dizemos poucas coisas em uma hora. Nós dizemos e fazemos poucas coisas? É relativamente pobre de fato...

18. Ch.: Pobre?

19. F.: Ao nível do conteúdo onde... talvez seja também eu que trabalhei em demasia sobre o método... então... mas agora isso me afeta.

20. Ch.: Mas você sente isso como uma contradição entre o tempo gasto no documento e...?

21. F.: Sim, sim, sim... Mas não forçosamente algo insolúvel, mas alguma coisa que eu tenho dificuldade de resolver... Ah mas é 
verdade que é uma coisa que já discuti muito com o meu tutor! é verdade que a entrada em atividade reduz fortemente o conteúdo. Eu me responsabilizo no que diz respeito à profundidade, mas de fato eu não sou muito apegada a isso. Eu penso que o importante é, de fato, o aprendizado da reflexão desses documentos. Que eles não tenham toda a cronologia na cabeça, todos esses detalhes e tudo o mais, não é muito grave, desde o momento em que eles sejam capazes de ter um recuo crítico sobre um documento, de responder, de compreender as instruções, isso me parece muito mais importante para eles que o resto. Eu tenho a impressão de que a partir do momento em que eles souberem ler as instruções, responder, organizar uma resposta, eles serão capazes de ler, não importa qual livro, onde essas informações se encontram. Eu quero dizer, é, é....

22. Ch.: Então, nesse caso, por que você se culpa pelo conteúdo?

23. F.: Porque eu ainda não resolvi esse problema.

24. Ch.: O que você quer dizer?

25. F.: Porque eu fico, eu penso sobre... Como dizer, ligada a... eu não sei... é... como dizer? É um pouco lugar-comum... eu não sei... Sim, eu penso que eu fico ligada a coisas antigas, talvez a meu... minha formação... ao curso universitário etc. e eu tenho muita dificuldade de me tirar a responsabilidade com relação à isso... eu não sei...

26. F.: Eu disse a mim mesma, mas espera, você se deixou submergir tanto pelo método, focalizou o método, que não tem mais conteúdo, enfim não tem conteúdo suficiente.

27. F.: Eu continuo a pensar sobre isso, é isso: O fato de ensinar um modo de reflexão toma um tempo enorme e se queremos leválos a refletir, a refletir bem, a construir uma reflexão, somos forçosamente obrigados a deixar pra lá, enfim, a deixar pra lá....

28. SC.: de relaxar quanto aos conteúdos.

29. F.: De relaxar quanto aos conteúdos....

30. SC.: Mais que os conhecimentos, é a reflexão... Os conhecimentos que você lhes dá, como base, não são falsos....

31. F.:Não são falsos, são muito simplificados.

32. SC.: O que está te faltando é o que é da ordem da reflexão do historiador, enfim, do historiador de modo abrangente. Não são conhecimentos que faltam.

\section{Anexo 2: notas de F., 2 anos depois da experiência}

1. O que foi mudado:

2. Antes de começar as reuniões do CNAM, eu tinha a impressão de ter conquistado alguma serenidade. Eu não ia mais dar aula como se tivesse com "uma bola na barriga" (ou de maneira pontual para turmas bem precisas). Aliás, essa angústia me teria feito mudar de profissão se ela não houvesse desaparecido. Mas depois que iniciamos esse trabalho, eu tenho o sentimento de ter conquistado uma verdadeira serenidade.

3. Eu senti a necessidade de abrir minha turma porque pressentia que me faltava um ponto de vista diferente.

4. Mudança profunda da minha relação com a profissão. Isso não se vê forçosamente no cotidiano, isso não revolucionou minha maneira de ensinar, mas provocou uma verdadeira transformação. Eu não ensino diferente, mas eu vivo meu ofício de outra maneira. Eu aceito melhor nem sempre ser perfeita. Eu não me situo mais com relação a um modelo, mas com relação à minha prática sem me culpar demais (não vamos exagerar). Eu me distanciei. Eu aceito também melhor o fracasso (o termo é um pouco demais) que eu seja responsável ou não, porque eu faço melhor a diferença entre o que é do domínio dos conflitos do ofício e o que pertence às minhas próprias carências (que podem ser múltiplas).

5. Liberação do olhar dos outros e da imagem que construímos dessa profissão quando debutamos nesse ofício.

6. Pacificação das relações com os alunos: tensão para a qual eu não via saída e que se resolveu a partir do momento em que eu identifiquei os conflitos como próprios da atividade.

7. Por exemplo: o barulho. A tensão inerente à confrontação entre um modelo e o que é realmente possível ser feito em classe desaparece assim que isso é identificado em termos de conflito de atividade exterior a si mesma: uma outra relação pode ser construída com a turma. Isso dito, não resolve totalmente o problema porque a relação (tolerância) com o barulho depende de muitos outros fatores, mas isso permite eliminar essa tensão parasita e ser mais sereno perante o barulho, de lhe dar uma função (nem sempre) e de se conscientizar que isso não é sempre sinônimo de fracasso.

8. O papel do diálogo:

9. Confrontação com os outros: nos enriquecemos com as reflexões, as experiências dos outros. Nos questionamos: por que eu não tentaria a mesma coisa para ver se dá certo? Como dizíamos com SC: "repare hoje, eu banquei o E., ou o SC (no que me diz respeito)": i. Portanto estamos descomplicados e tentamos outras coisas. Não faz mal se não funcionar; ii. Modificamos a nossa prática sobre elementos que até então eram problemas e para os quais não tínhamos solução.

10. Confrontação consigo mesmo:

11. Confrontação com o pesquisador: não poderíamos falar dele como "aquele que para"?

12. O processo de maturação:

13. Construção progressiva: As coisas são ditas/descritas. Em seguida, tem-se um amadurecimento interior. Depois que os outros propõem as soluções, elas parecem válidas, mas não eliminam a culpabilidade. É preciso conseguir colocar palavras sobre uma situação: ao mesmo tempo as palavras justas, e ter coragem de dizer, quer dizer, aceitar enfim o que realmente aconteceu.

14. Olhando o vídeo (extraído do curso + confrontação simples + autoconfrontações cruzadas).

15. Impressão de um amadurecimento, mas cujos efeitos só aparecem no momento em que se assiste aos vídeos, o que me permitiu confrontar novamente meu propósito e esclarecer meu ponto de vista.

16. Sobre o vídeo: confusão entre conteúdo e conhecimento. Ideia de que o aprendizado do método ou a entrada em atividade (aí também eu faço a confusão) é incompatível com o que traz o conteúdo.

17. Hoje: a entrada na atividade e o aprendizado de métodos de reflexão não necessitam de uma importante contribuição de conhecimentos (fatos, cronologia...), mas permitem transmitir os conteúdos (conceito, por exemplo).

18. Assistir o vídeo leva também a um momento onde eu trabalho um capítulo de 1STT sobre o conceito do totalitarismo. Apesar da complexidade desse conceito e do baixo nível de abstração dos meus alunos, eu decidi mostrar-lhes que esse conceito é operacional em certos aspectos dos exemplos estudados, mas não para tudo (e portanto lhes fazer refletir sobre a validade do conceito). Me foi necessário fazer escolhas quanto à massa de conhecimentos para não me prender apenas ao conteúdo, mas ao que faz sentido. Eu fiz sem nenhuma hesitação, pela primeira vez.

19. Duas possibilidades (eu não havia destrinchado): i. Ver o vídeo e o trabalho de reflexão pedagógica fez eco e me permitiu clarificar minha posição e resolver esse conflito; ii. Se eu modifiquei minha estratégia pedagógica, é porque minha reflexão já tinha resultado, mas eu não tinha tido a ocasião de formulá-la com clareza. 